

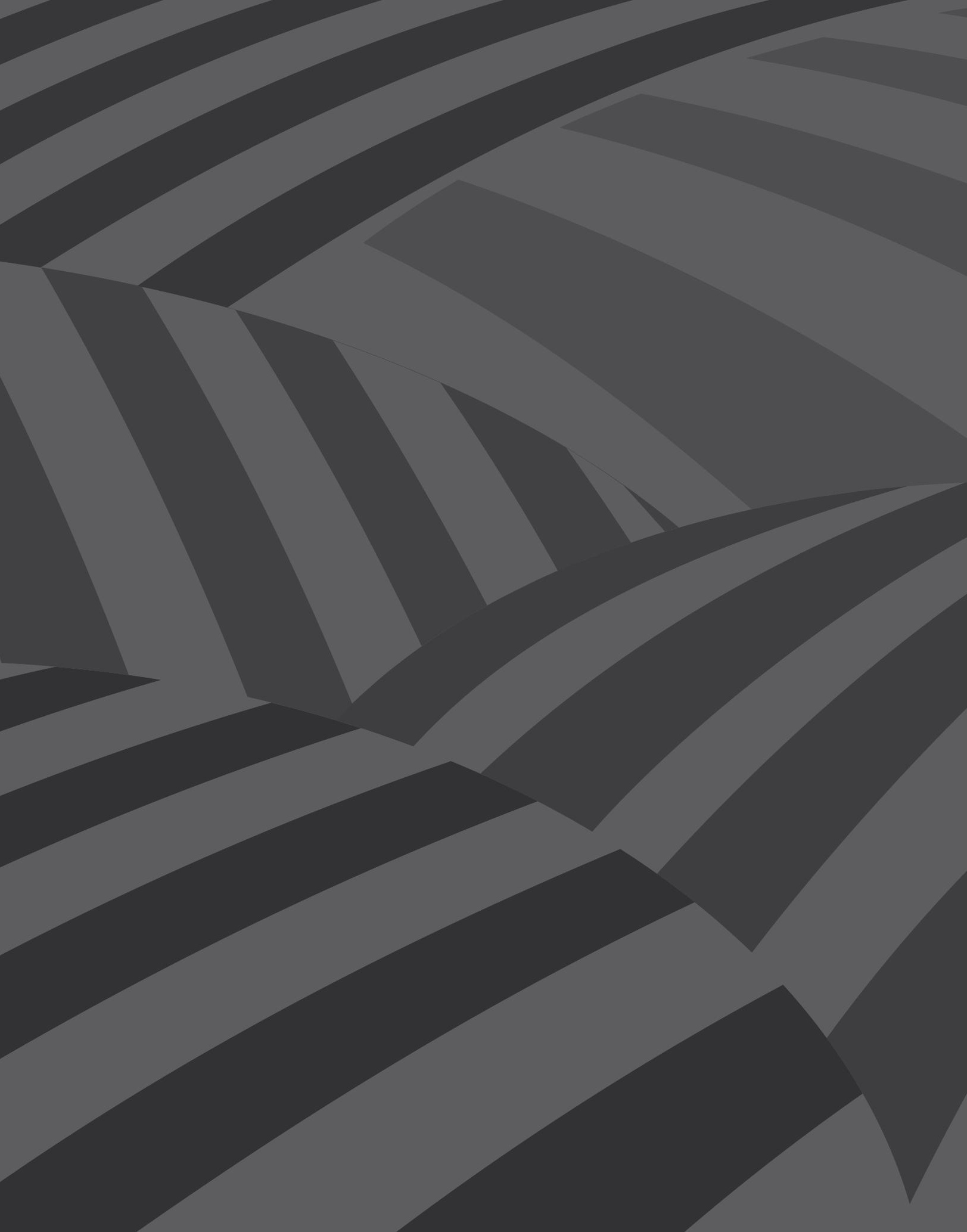




\title{
Memoria, verdad e historia oral
}

\author{
Por Mauricio Archila*
}

Resumen: Colombia está viviendo un momento histórico debido a la superación del prolongado conflicto armado. En este artículo se reflexiona sobre uno de los componentes centrales de los acuerdos de paz de La Habana: el derecho de las víctimas colombianas a la verdad, la justicia, la no repetición y a una vida digna. Este tema se conecta con la historia oral, pues ella juega un papel clave en la reconstrucción de las memorias de las víctimas y, en general, de los grupos subalternos. En consecuencia, este texto responderá a tres preguntas: ¿de qué memorias hablamos y cómo se relacionan con la disciplina histórica?, ¿cuál es la verdad a la que apuntan los trabajos de la memoria?, ¿qué papel juega la historia oral en estos procesos? De esta forma, los historiadores y estudiosos del pasado no están ausentes en este momento crucial del país.

Palabras clave: memoria, verdad, historia oral, víctimas, historiadores.

\section{Historical memory, truth and oral history}

Abstract: Colombia is going through a historical moment after overcoming a prolonged armed conflict. This article reflects on one of the central components of La Habana peace accords: Colombian victims' rights to truth, justice, no repetition, and a dignified life. This issue is connected with oral history, since it plays a key role in reconstructing the victims' and, on the whole, subaltern groups' historical memories. As a result, this text will answer three questions: What kind of historical memories are we referring to, and how are they related to History as a discipline? Which truth do historical memory studies aim at? What role does oral history play in these processes? Thus, historians can take part in this crucial historical moment for our country.

Keywords: historical memory, truth, oral history, victims, historians.

Cómo citar este artículo: Archila, Mauricio (2017). Memoria, verdad e historia oral. Revista Controversia, 209, 21-39.

Fecha de recepción: 25 de julio del 2017

Fecha de aprobación: 15 de noviembre del 2017

* Ph. D. en Historia, profesor titular de la Universidad Nacional de Colombia, sede Bogotá, e investigador asociado del Cinep. 
“[...] los historiadores son algo así como los custodios no solo del pasado, sino de la ‘conciencia histórica' de la ciudadanía” (Carretero, 2007, p.175).

\title{
Introducción
}

\begin{abstract}
olombia está viviendo un momento crucial en su historia, pues está ad portas de superar el conflicto armado que por más de sesenta años la ha consumido. Los estudiosos del pasado no están ausentes en esta coyuntura histórica y, como señala Mario Carretero, hablando de los usos públicos de la Historia, tienen varias funciones que cumplir, especialmente en relación con la "conciencia histórica" de la ciudadanía. Tal es el trasfondo de las reflexiones de este artículo.
\end{abstract}

Es cierto que los acuerdos de La Habana con las FARC (Fuerzas Armadas Revolucionarias de Colombia) ${ }^{1}$ sufrieron un golpe con la derrota del plebiscito aprobatorio por un pequeño margen el 2 de octubre de 2016 y que, de todas formas, no significan el fin de toda violencia política, pues aún se está negociado con otra guerrilla histórica, el ELN (Ejército de Liberación Nacional), y, además, subsisten grupos paramilitares y bandas narcotraficantes, pero sin duda estamos ante una oportunidad única. En este artículo reflexionaremos sobre uno de los componentes centrales de dichos acuerdos: el derecho de las víctimas del conflicto armado colombiano a la verdad, la justicia, la no repetición y a una vida digna. Las víctimas son casi una cuarta parte de la población del país, 8000000 de personas - la gran mayoría son desplazados internos-, $\mathrm{y}$, generalmente, se ubican en los sectores sociales más explotados y excluidos de la sociedad. Pretendemos conectar este tema con la historia oral, pues ella juega un papel clave en la reconstrucción de las memorias de las víctimas y, en general, de los grupos subalternos. De dichas memorias saldrán los múltiples relatos del pasado, algo que es un reto ético y político para los historiadores. Todo ello en el marco de la construcción nacional de memoria histórica, especialmente de las víctimas,

1 Hoy llamadas, en singular, Fuerza Alternativa Revolucionaria del Común. 
a través de la recién creada Comisión de Esclarecimiento de la Verdad, la Convivencia y la No Repetición (CEV de ahora en adelante), fruto de los acuerdos de La Habana. En consecuencia, este texto responderá a tres preguntas: ¿de qué memorias hablamos y cómo se relacionan con la disciplina histórica?, ¿cuál es la verdad a la que apuntan los trabajos de la memoria?, ¿qué papel juega la historia oral en estos procesos?

\section{1) Memorias e historias}

Para los historiadores es claro que el pasado está relacionado con el presente y, de alguna manera, desde allí se proyecta al futuro. El presente sería esa intersección entre lo que Koselleck (1993) llama el espacio de la experiencia y el horizonte de expectativas. No en vano los fundadores de la escuela de los Annales, en su disputa con el historicismo decimonónico, reclamaban que toda historia es presente. En ese sentido, la historia se nutre de él y vuelve a él para, en palabras del historiador marxista británico Eric Hobsbawm, impedir que el presente sea una mera repetición del pasado (1998). Por su parte, Enzo Traverso dice: "la memoria se conjuga siempre en presente” (2007, p. 18), en consecuencia, se trata de invocar un radical "nunca más", ahora en el terreno de la historiografía.

Pero no pensamos en cualquier memoria, resaltamos la de los que genéricamente se llaman los vencidos, los excluidos de la historia, cuya voz ha sido silenciada por la "enorme condescendencia de los tiempos" (Thompson, 1963, p.12). Hoy hablaríamos de los subalternos y de las víctimas, quienes, por medio de los "trabajos de la memoria”, quieren salir de la condición que los vence, excluye y victimiza, y, por ese camino, buscan controlar su presente desde el reconocimiento del pasado para así proyectar un futuro distinto. Pero hilando más delgadito hay muchos matices de la memoria, pues ella no es una sola, incluso si se trata de la de los subalternos. Brevemente resumiremos esos matices para luego elaborar sobre sus relaciones con la disciplina histórica. 
Convencionalmente se entiende la memoria como el recuerdo del pasado traído al presente. Es algo más que un reflejo pasivo ante un estímulo externo como un olor o un color; se trata de una acción, un "trabajo" intencional de revivir el pasado en el presente (Ricoeur, 2008). Pero no es todo pasado, sino aquel que es significativo para un individuo o para un colectivo. Es una materia viva que parte de la experiencia subjetiva, se recrea y transforma según los contextos, intereses y poderes del presente. Para Maurice Halbwachs (2004) la memoria, si bien se puede ejercer individualmente, siempre está inscrita en marcos sociales.

Para mirar los matices de la memoria retomamos la distinción que Enzo Traverso (2007, cap. 2) hace entre memorias "fuertes" - generalmente oficiales o hegemónicas - y memorias “débiles” — aquellas ocultas o reprimidas y, en todo caso, subordinadas, que algunos llaman memorias disidentes (Gnecco y Zambrano, 2000) - . Evidentemente, esto refiere a disputas por el significado del pasado que reproducen las luchas por el poder en una sociedad determinada. Y hay casos de inversión en los que la fuerte se debilita y la débil se fortalece. Lo ocurrido en Occidente con el Holocausto puede ser un ejemplo de una memoria disidente que se vuelve hegemónica. Pero habría que aclarar que no toda memoria sobre el Holocausto es hegemónica, pues una es la que se fortalece en torno, por ejemplo, al museo en Washington DC - a despecho de la ausencia de museos sobre la esclavitud o el aniquilamiento de los indígenas norteamericanos - y otra la memoria cada vez más débil, según Traverso (2007, p.91), del antifascismo. Pero no nos adelantemos a la necesaria crítica que debe hacerse de cualquier memoria.

Otra distinción útil es entre memorias excluyentes e incluyentes. Según Elizabeth Jelin (2003), las primeras están referidas a la experiencia particular, mientras las segundas son más generales². La autora utiliza la

2 Ella trae a colación dos palabras guaraníes que significan ambas "nosotros”, pero con distinta cobertura: "ore" es el nosotros comunitario y "Ñande" el más amplio que incluye también a los cercanos (Jelin, 2003, p.45). 
terminología de Tzvetan Todorov, quien distingue entre memoria "literal” - la que no va más allá del testigo y es intransferible- y la "ejemplar” —que busca ir más allá de la anterior para generalizarse-. Ahora bien, la apuesta de Todorov (2000) es ligar memoria con justicia, por lo que tiende a privilegiar la “ejemplar”, puesto que esta permite ligar el pasado con el presente para propiciar la explicación de lo ocurrido.

En la terminología construida a raíz del Holocausto, se suele asociar la memoria "literal” con el "musulmán" — la víctima que no puede hablar de su experiencia, pues encarna lo indecible- y la "ejemplar” con el "sobreviviente" —el testigo que habla para que otros oigan-. En los planos más amplios de la construcción testimonial se asocia a la memoria "literal" con la víctima, y a la "ejemplar" con el observador, en muchos casos el historiador o el científico social, pero también puede ser el intelectual “orgánico” de los movimientos sociales, es decir, todo aquel que trace una distancia con la experiencia vivida, así simpatice con la víctima. Mucho antes del Holocausto, o de que este se conociera públicamente, Walter Benjamin distinguía entre la experiencia vivida y la transmitida. Él presintió que la modernidad occidental ponderaría cada vez más la primera por los traumas que soportaría a lo largo del siglo xx (Traverso, 2007, pp.14-15).

Aquí es necesario afirmar con Jelin (2003, cap.5) que ninguna memoria es más verdadera que otra, son distintas formas de rememorar el pasado. Para Dominick LaCapra, la distinción es entre memoria primaria - "la de una persona que ha pasado por acontecimientos y los recuerda de una determinada manera”- y memoria secundaria — “el resultado de un trabajo crítico con la primaria”-(2009, p. 35). A su juicio, ambas se influyen mutuamente y la secundaria puede ser internalizada por la primaria. Por ello "ningún recuerdo es puramente primario", pues siempre estará mediado por elementos externos (LaCapra, 2009). La memoria "literal" o primaria de las víctimas puede servir para fortalecer lazos comunitarios y construir identidades frente a los externos, mientras la "ejemplar” o secundaria puede hacer más universal la experiencia y 
fortalecer alianzas con los otros distintos. La primera parece estar más cercana a posturas esencialistas en la construcción de identidades, mientras la segunda se acerca a cierto pragmatismo antiesencialista en la labor identitaria y es ciertamente un puente con el trabajo del observador.

Vistos los distintos acentos sobre las memorias subalternas -especialmente entre la primaria, vivida o literal, y la secundaria, transmitida o ejemplar-, conviene abordar la relación entre la disciplina histórica y la memoria. Digamos de entrada que, si bien ambas elaboran el pasado, lo hacen en forma diferente. La razón occidental tradicionalmente ha sospechado de la subjetividad, particularidad e inmediatez de la memoria por lo que exige una disciplina - la Historia - para contextualizarla, criticarla y, sobre todo, para hacerla comprensible en forma más universal. Así, la memoria recordaría, la historia explicaría. La primera es un acto subjetivo para darle sentido a la existencia individual y colectiva, la segunda hace parte del campo científico y pretende ser objetiva. Hoy en día algunos teóricos plantean que historia y memoria tienen una relación complementaria o de colaboración, pues ambas trabajan el pasado, mientras otros enfatizan el antagonismo entre ambas por su distinto acercamiento a lo pretérito. Los enfoques varían, no solo por la perspectiva teórica de los autores, sino por las prácticas para reconstruir el pasado. Veamos.

Dentro de la primera perspectiva se suele recurrir a Paul Ricoeur, para quien la memoria es la madre de la Historia - ambas trabajan la "presencia del ausente: el pasado” (2008, p.118) - , pero terminan diferenciándose cuando la última se conforma como campo disciplinar. La memoria como labor de recordar está ligada a la experiencia subjetiva, mientras la Historia es un ejercicio académico que toma distancia de esa experiencia en su afán de comprenderla. Según el historiador español Julio Aróstegui (2004, p.158), son dos tipos de “registros” del pasado, con distintos niveles interpretativos, porque ambos interpretan. Tanto la memoria como la historia - al menos en la versión actual de esta disciplina- buscan ofrecer relatos verdaderos del pasado, pero la 
primera se liga a la experiencia (subjetiva) y la segunda a la comprensión distanciada (no necesariamente “objetiva”).

Ahora bien, la relación entre memoria e historia no es siempre vista como colaboración. No faltan quienes insisten en que la idea de comprender la experiencia o de "historizar la memoria" — según expresión de Aróstegui (2004) - es una visión occidental que conlleva una supuesta superioridad de la disciplina histórica, lo que no es otra cosa que "colonizar" la memoria. Aunque existe el riesgo de esta colonización, para nosotros, siguiendo a Elizabeth Jelin (2003), se trata de dos regímenes distintos de verdad, sin que uno sea superior al otro. Beatriz Sarlo va más lejos al criticar la deificación del testimonio basado en la experiencia personal como si este fuera más verdadero per se: la memoria puede ser un impulso moral de la historia, pero eso no significa que contenga una verdad indiscutible (Sarlo, 2005, p.57, ver también p.63). Para ella, el sujeto que narra en el testimonio se aproxima a una verdad que solo conoce en fragmentos, por eso se requiere de la otra verdad que entienda esos fragmentos, la verdad de la comprensión. Por tanto, ella pondera la labor del historiador al afirmar, apoyándose en Susan Sontag: “es más importante entender que recordar, aunque para entender sea preciso, también, recordar” (Sarlo, 2005, p.26).

\section{2) Historia oral y las memorias ${ }^{3}$}

Ahora bien, veamos qué papel juega la historia oral en los procesos de recuperación del pasado. Mucho se ha insistido en que, y no abundaremos en ello, la memoria colectiva da sentido de pertenencia a los grupos humanos, les refuerza sus raíces, recupera su historia cuando ha sido negada, y su voz cuando ha sido silenciada. Por esa vía, las memorias subalternas - que incluyen las de las víctimas - reafirman las identidades colectivas que, como es bien sabido, no son naturales, sino que

3 Para las siguientes secciones retomo elementos del artículo Voces subalternas e historia oral (Archila, 2005) actualizándolos para el caso colombiano del momento. 
se construyen en medio de los conflictos enfrentados en su cotidianidad (Archila, 2003, cap.7). Por esa vía, reconstruyen la historia de los llamados pueblos “sin Historia”. Como lo señala Ranahit Guha, a medida que la modernidad occidental fue imponiéndose por la expansión del capitalismo, fue subyugando a los pueblos sometidos, no solo por medio de relaciones coloniales de dominación, sino a través de su catalogación como pueblos "sin Historia”, por no tener escritura o, según Hegel, por no tener un Estado moderno (Guha, 2002). En esta encarnación de la razón occidental se produce una sintomática asociación entre historia, escritura y Estado, asociación que ha marcado el devenir de la historiografía como acertadamente critican los subalternistas. Guha advierte que el Estado de la modernidad occidental, de manera creciente, pretende expropiar el pasado a los pueblos sometidos negándoles su historia y controlando su memoria - por ejemplo, a través de los archivos y de los museos estatales-. Pero esa memoria subalterna no se dejó someter y se convirtió en la reserva de las luchas anticoloniales, esa que busca expropiar a los expropiadores de su pasado ${ }^{4}$. Dicha tarea nunca termina, pues, como dice Walter Benjamin, el "enemigo nunca ha cesado de vencer” (1995, p.51).

Uno de los mejores caminos para llegar a las memorias subalternas es la historia oral. Ella es algo más que una técnica de investigación,

4 Algo similar decía Gabriel García Márquez en un congreso de intelectuales en La Habana a finales de los años ochenta: “[...] Por fortuna la reserva determinante de la América Latina y el Caribe es una energía capaz de mover el mundo; es la peligrosa memoria de nuestros pueblos. Es un inmenso patrimonio cultural anterior a toda materia prima [...] Es una cultura de resistencia que se expresa en los escondrijos del lenguaje, en las vírgenes mulatas - nuestras patronas artesanales-, verdaderos milagros del pueblo en contra del poder clerical colonizador. Es una cultura de solidaridad, que se expresa ante los excesos criminales de nuestra naturaleza indómita, o en la insurgencia de los pueblos por su identidad y su soberanía. Es una cultura de protesta [...] Es una cultura de fiesta, de trasgresión, de misterio, que rompe la camisa de fuerza de la realidad, y reconcilia por fin el raciocinio y la imaginación, la palabra y el gesto, y demuestra de hecho que no hay concepto que tarde o temprano no sea rebasado por la vida" (discurso publicado en El Espectador, 16 febrero de 1986, p.17, el subrayado es nuestro). 
pero algo menos que una nueva corriente historiográfica. Por supuesto cuestiona las disciplinas sociales, al plantear no solo nuevas fuentes de conocimiento, sino una relación más horizontal con los investigados y, por esa vía, contribuir a empoderarlos como sujetos de su devenir. Pero muchos de los que la utilizamos no la consideramos una corriente historiográfica o epistemológica radicalmente diferente de las que existen. Y, en ese sentido, no hay razón para decir que la historia oral es superior a otras formas de practicar el oficio de historiador, como tampoco puede considerársela como una labor inferior o secundaria ante otros métodos de acercarse al pasado. Todo depende del objeto y enfoque de la investigación. Yo, de hecho, la he usado como historiador social, y la he encontrado muy útil en mis pesquisas con grupos o movimientos sociales que no han dejado mucha documentación escrita o que son analfabetos. También me ha servido para dar luz a aspectos menos épicos de la vida cotidiana, especialmente las dimensiones simbólicas y culturales. En otra parte he hablado de mi experiencia concreta en este campo (Archila, 1998), aquí quiero concentrarme en los alcances de la historia oral en la reconstrucción de las memorias subalternas, en las que incluyo a las de las víctimas.

Algo muy común es proclamar que la historia oral da voz a los sin voz. Esto lo he comprobado desde la práctica simple de entrevistar ancianos que sienten que pueden volver a hablar sin ser rechazados, incluso por sus familias cansadas de oír sus repetitivos "cuentos". Pero es justo interrogarse sobre qué significa eso de "dar voz a los sin voz". De una parte, es obvio que se trata de algo metafórico, pues en general los subalternos no pierden la voz, sino que no son escuchados o su voz ha sido silenciada. Por otra parte, y más a fondo, hay que volver al desafío que hace años lanzó la filósofa india Gayatri Ch. Spivak (2003): ¿habla el subalterno?, o ¿quién habla cuando habla el subalterno?, o La segunda pregunta es una forma de responder la primera: a juicio de Spivak el mundo subalterno es irreductible a las categorías hegemónicas occidentales, y cuando el subalterno las usa para ser escuchado, ya no habla él estrictamente, sino las formas coloniales de mediación con las 
que se expresa. Por esa vía, que respira la búsqueda esencialista de una subalternidad pura e incontaminada, podemos llegar al silencio total del subalterno, algo que nos recuerda la figura del "musulmán” en los campos de concentración nazis.

Por fortuna no todos comparten esa postura de silenciamiento de los subalternos, pues no solo anularía el oficio del historiador, observadorsobreviviente, sino que difícilmente se podrían hacer los trabajos de la memoria "ejemplar” y aun "literal”. Sin responder directamente al desafío de la Spivak, Boaventura de Sousa Santos (2009, cap. 3) nos propone la labor de traducción en un horizonte relacional en el que ninguna cultura es completa, por lo tanto, necesita de las otras, que también son incompletas. La razón occidental en forma “indolente”, a su juicio, se considera completa y, por ello, niega a las otras culturas, crea las ausencias - los silencios-, las borra de la historia. Para el sociólogo portugués, la forma de hacer visibles estas ausencias es mediante la traducción entre distintos saberes, sin que por esencia uno sea superior al otro. Así, el subalterno traduce continuamente, pero todos sabemos que la traducción tiene algo de traición y puede favorecer al conocimiento hegemónico, máxime si el diálogo se hace en la lengua imperial.

Más situados en nuestro subcontinente, intelectuales como Paulo Freire, Orlando Fals Borda y los teólogos de la liberación consideran que el subalterno, el oprimido, no solo puede hablar, sino que debe hacerlo. Por su parte, la socióloga boliviana Silvia Rivera afirma que el subalterno sí puede hablar, pero no de cualquier forma ni ante cualquier público “otro”. A ese respecto trae a colación la experiencia del Taller de Historia Oral Andino, en el cual intelectuales aymaras y no-aymaras, hablando la lengua de los primeros, recuperan su pasado, descolonizándolo no solo en el contenido, sino en la forma. Para ella, el problema no es si el subalterno habla, sino si es escuchado cuando habla (2004, pp.2126). Y este es el punto clave en el debate con Spivak. Nosotros creemos que el subalterno habla, pero cómo habla y, sobre todo, cómo es 
escuchado, estas son dos preguntas cruciales para nuestro oficio, preguntas que, a su vez, tienen consecuencias éticas y políticas.

Y es que, como se percibe en estos debates sobre la contribución de las memorias subalternas a las identidades colectivas, subyace una profunda dimensión política en todos los trabajos de la memoria. No solo porque ella se inscribe en la disputa por el significado del pasado, sino porque, para muchos colectivos y movimientos sociales, la memoria es una forma de legitimar su lucha presente. Así lo ha demostrado, por ejemplo, Joanne Rappaport (1990) para el caso de los indígenas del Cauca. Para ella, intelectuales como Juan Tama, Manuel Quintín Lame y muchos de los dirigentes indígenas actuales de la región, no solo tienen otras nociones de tiempo y espacio, sino que trabajan la memoria en función de su presente. Incluso, lo hacen explícitamente para legitimar sus luchas actuales.

Es cierto que las memorias subalternas tienen límites. Las “literales”, ligadas a la experiencia vivida de la víctima, pueden ser no solo excluyentes, sino encerrarse y volverse intransmisibles. A su vez, las "ejemplares” arriesgan perder el calor de la experiencia terminando en una nueva abstracción de la subalternidad, cuando no en la banalización de las víctimas. En todo caso, se impone un trabajo de crítica a las memorias subalternas sin deificarlas, lo cual no las anula como formas legítimas de representar el pasado. Esta crítica, por supuesto, debe extenderse al uso de toda fuente, sea escrita u oral.

\section{3) $\operatorname{Verdad}(e s)$}

Mucho hemos hablado sobre la existencia de distintos regímenes de verdad, tanto entre memoria e historia como dentro de las distintas memorias subalternas, especialmente la literal o vivida y la ejemplar o transmitida. Es bueno preguntarse qué entendemos por verdad. 
Partimos del supuesto de que, como dice Eric Hobsbawm (1998), los hechos no son pura ficción y se produjeron más allá del historiador. De entrada, esto marca distancia con corrientes posmodernas que insisten en que los hechos tienen mucho de ficción literaria y son construcción de los colectivos humanos y especialmente de los historiadores. De ser así nos quedaríamos, usando una metáfora de Laurence Stone (1991, p.217), en un cuarto de espejos mirando la proyección infinita de nuestra imagen, pero sin considerar lo que está más allá de los espejos, eso que solemos llamar la realidad.

Ahora bien, que los hechos existan o hayan existido más allá de los historiadores no quiere decir que podamos llegar a ellos como si calcáramos la realidad. Ese sueño positivista de la escuela de Von Ranke no es posible. La verdad histórica es reconstruida a partir de las huellas que dejaron los hechos, pero también de las preguntas e hipótesis que formulen los historiadores. Como bien lo ha expresado E. P. Thompson (1981), se trata de un diálogo no exento de tensiones entre dato empírico y teoría. Más aún podemos decir que casi desde que se produce el dato o la huella, ya hay alguna interpretación por parte del testigo o del escribano. Luego, el almacenamiento y clasificación de esas fuentes en los archivos también está marcado por lecturas del pasado, en este caso desde las agencias estatales y los intereses privados que promueven tales depósitos de la memoria. Y, en fin, el trabajo del historiador consistirá en interrogar esas fuentes y tratar de comprenderlas desde sus hipótesis y elementos teóricos. Y, por supuesto, la validación del conocimiento producido pasa por las comunidades involucradas, entre ellas las de los académicos. En ese sentido, la verdad histórica es múltiple y plural, por eso será siempre vano el intento de hacer una historia única y oficial. Pero al mismo tiempo los historiadores no cejamos en buscar esas verdades, pues de eso se trata nuestro oficio (Archila, 1999).

Obviamente, esa búsqueda hace parte de las disputas por el pasado que encierran luchas por el poder. El mismo Hobsbawm ha mostrado el potencial destructivo que tiene el uso y el abuso del pasado a favor de 
causas raciales o nacionalistas. El negacionismo, por supuesto, afectará la credibilidad del trabajo histórico, por ejemplo, ante el Holocausto (Habermas 1989), o en el caso colombiano, la negación de que existe un conflicto armado. En estos casos no solo se busca hacer una historia que moldea los hechos "negativos" para volverlos "positivos" -que puede ser un cierto tipo de "revisionismo" (Traverso 2007, cap. 6)-, sino que incluso ignora los hechos. Eso último es el extremo del negacionismo. Algo similar ocurre hoy con la famosa "posverdad" que no es sino la reencarnación del viejo adagio de "mentir, mentir contra toda evidencia”; obviamente se lanza con fines políticos, como incentivar el odio racial y construir muros contra la inmigración en el imperio del norte, romper la Unión Europea y toda la idea de cosmopolitismo que allí se encerraba para exacerbar el viejo nacionalismo, o enterrar los acuerdos de paz con la insurgencia en Colombia para retroceder a una época de guerra que beneficia a unos pocos halcones militares, políticos y empresariales.

Pues bien, existe una antigua relación entre historia y justicia, sobre todo en vertientes que hacen explícita su opción ética por un conocimiento del pasado que impida su repetición. Durante mucho tiempo se asimiló el papel del historiador con el del juez. Más aún, ambos comparten la búsqueda de la verdad y, principalmente, la necesidad de la prueba. Pero como dice Carlo Ginzburg (1993, p.21), el historiador no es el juez: su tarea no consiste en juzgar, sino en comprender 5 . Y complementa Traverso, la verdad del historiador "no tiene un carácter normativo, es imparcial y provisional, jamás definitiva ([...] en cambio) la verdad de la justicia es normativa, definitiva y coactiva” (Traverso, 2007, p.66). En síntesis, es una verdad de comprensión y explicación, no de juicio y sanción. En ese sentido, la prueba tendrá distintas implicaciones para el

5 Más adelante dice: “El camino del juez y el del historiador, coincidentes durante un tramo, luego divergen inevitablemente. El que intenta reducir al historiador a juez, simplifica y empobrece el conocimiento historiográfico; pero el que intenta reducir al juez a historiador contamina irremediablemente el ejercicio de la justicia” (Ginzburg, 1993, p.112). 
juez o para el historiador: para el primero será más positiva y demostrativa, para el segundo será más conjetural y explicativa ${ }^{6}$.

Evidentemente cuando esto se traslada a una instancia oficial, o al menos pública, como una comisión de verdad creada para cerrar un conflicto armado, se vuelve más complejo, pues hay expectativas de las víctimas de uno u otro bando para que se esclarezca la verdad. Y aunque hay experiencias en que el enfoque de esas comisiones ha sido más judicial, por lo común obran en el terreno de la verdad histórica, aunque con implicaciones penales (González y Varney, 2013).

Según un experto del Centro Internacional para la Justicia Transicional, una comisión de la verdad es "una comisión investigadora autónoma, centrada en las víctimas, establecida ad hoc en un Estado (y autorizada por el mismo Estado), cuyas funciones primordiales son 1) investigar e informar sobre las causas principales y las consecuencias de patrones amplios y relativamente recientes de severa violencia o represión que hayan ocurrido en dicho Estado durante un período determinado de régimen autoritario o de conflicto armado, y 2) presentar recomendaciones para corregir dichas violaciones y prevenir que ocurran en el futuro" (Freeman , s.f) 7 . De modo que las tareas principales de tal comisión son investigar las causas y consecuencias de los hechos de

6 Los acuerdos de La Habana acertadamente crean un Sistema Integral de Verdad, Justicia, Reparación y no Repetición en el que los trabajos de la CEV se articulan con los de la Justicia Especial de Paz — JEP- y con la Unidad de Búsqueda de Personas Desaparecidas. Así, el componente histórico y el judicial caminan de la mano para fortalecerse mutuamente en favor de las víctimas. Esta novedad no se había presentado en anteriores comisiones de estudio de la violencia (Jaramillo, 2014).

7 El autor es Mark Freeman y el artículo se titula "África y sus comisiones de verdad y reconciliación”. Apareció en el Boletín de la Acnur, Hechos del Callejón (sin año). Consultado el 21 de junio de 2017 en http://www.acnur.org/t3/uploads/ pics/1720_2.pdf?view $=1$ 
violencia y dar recomendaciones para que esos hechos no se repitan ${ }^{8}$, no tanto condenar a $\mathrm{X}$ o $\mathrm{Y}$ victimario.

Pero además no sobra recordar que, por lo hasta ahora señalado, difícilmente reconstruiremos una verdad única y menos oficial de una historia tan compleja como lo es la de la violencia en Colombia ${ }^{9}$. En nuestro caso, y haciendo eco de algo expresado por el jefe de los negociadores de La Habana, Humberto de La Calle, es urgente pensar más que en una verdad que arroje conocimiento sobre el conflicto armado, que siempre será necesaria, en una verdad de "reconocimiento" del conflicto armado, de las víctimas y de los victimarios, una verdad "reparadora” que nos permita iniciar un camino de no repetición y de convivencia.

\section{Conclusión}

Los trabajos de la memoria desde las víctimas y la sociedad en su conjunto son cruciales para la búsqueda de verdad, justicia y reparación. Si en la Europa de la segunda posguerra fue más largo el silencio sobre el trauma - algunos autores dicen que solo hasta los años sesenta afloró

8 En el caso colombiano, los acuerdos de La Habana agregan la función de estimular la convivencia para producir la reconciliación nacional: "la Comisión de Esclarecimiento de la Verdad (CEv) deberá garantizar la participación de las víctimas, asegurar su dignificación y contribuir a la satisfacción de su derecho a la verdad, y en general, de sus derechos a la justicia, la reparación integral y las garantías de no repetición. Lo anterior debe contribuir además a la transformación de sus condiciones de vida" (Preámbulo del Decreto 588 de abril de 2017, por el cual se organiza la Comisión de Esclarecimiento de la Verdad, la Convivencia y la No Repetición).

9 Acertadamente, el Grupo de Memoria Histórica colombiano - GMH - en su informe general titulado Basta Ya dice: "Este informe no es una narrativa sobre un pasado remoto, sino sobre una realidad anclada en nuestro presente. Es un relato que se aparta explícitamente, por convicción y por mandato legal, de la idea de una memoria oficial del conflicto armado. Lejos de pretender erigirse en un corpus de verdades cerradas, quiere ser un elemento de reflexión para un debate social y político abierto" (GMH, 2013, p.16). A juicio de Jefferson Jaramillo (2014), las contribuciones del GMH son indudables y serán un insumo sustancial para la CEV, que debe partir de los análisis de caso para buscar patrones comunes de victimización y debe integrar el trabajo académico del mismo GMH y de muchos violentólogos con el mundo de las víctimas. 
públicamente la memoria-, en los países del Cono Sur que sufrieron dictaduras entre los años sesenta y los ochenta el silencio no fue tan prolongado, aunque se obstaculizó la rememoración en aras del espíritu de concordia que presidía las transiciones democráticas, al menos en los años noventa. Si en la Europa de la posguerra y en el Cono Sur de los ochenta, se quiso "normalizar" la sociedad domesticando el pasado, es decir, silenciando lo negativo, en los últimos tiempos lo "normal" en esas sociedades es, según Elizabeth Jelin, “confrontar y abrir la caja del pasado” (2007, p.333).

En Colombia, el trauma aún está vivo, porque no hemos salido del conflicto. No se ha dicho todo lo decible y lo indecible sobre él. No se ha hecho el duelo necesario. Pero lo más grave es cómo a esa memoria “débil”, subalterna o reprimida de las víctimas se le intentan superponer versiones oficiales que niegan o banalizan el daño, aduciendo que no hay conflicto armado, sino una guerra del terrorismo contra la sociedad; o que si existe dicho conflicto es marginal, pues los paramilitares se entregaron y la insurgencia está aniquilada. Tampoco faltan voces oficiales para las cuales la violencia política es un problema de celos o de roces entre vecinos. Igualmente, no se permite el duelo porque muchos han "desaparecido" y no se sabe de ellos; porque al haber una impunidad generalizada no aparecen los responsables, y, si se denuncian, no son juzgados, y, si son juzgados, escasamente son condenados. Además, cuando unos pocos son condenados, suelen ser conducidos a prisiones de lujo o se les da "casa por cárcel”. En suma, se quiere "normalizar" a la sociedad colombiana cuando aún el trauma está vivo, y no solo en la memoria del pasado, sino en la vida cotidiana del presente: los grupos paramilitares siguen existiendo así el Estado no los reconozca como tales y eufemísticamente los llame Bacrim (Bandas Criminales). Las FARC se han desmovilizado y desarmado - iesto es un hito histórico! - , pero van surgiendo disidencias mientras la otra guerrilla, el ELN, inicia diálogos de paz con muchos tropiezos y con un calendario electoral encima. Por todo lo anterior, en Colombia todavía es difícil creer en un "nunca más”... 
Pero hay razones para tener un moderado optimismo: estamos ante una posibilidad única de romper la maldición de nuestros cien años de soledad, para así tener una segunda oportunidad sobre la tierra y construir la sociedad que soñamos - al menos una en la que no nos matemos por nuestras diferencias políticas o ideológicas-. En ese orden de ideas, es fundamental el trabajo de reconstrucción de las diversas memorias apuntándole a una verdad histórica que nos permita entender lo que pasó, complementada con una verdad judicial que condene a los responsables y permita generar una nueva conciencia ciudadana, capaz de reconocer a las víctimas y de llegar a la superación de la cultura excluyente que nos caracteriza. Tal es el horizonte que tiene trazada la CEV, allí será fundamental la colaboración de los estudiosos del pasado en el espíritu de las palabras iniciales de Mario Carretero.

\section{Referencias}

Archila, Mauricio (1998). Fuentes orales e historia obrera. En T. Lulle, P. Vargas y L. Zamudio (Eds.). Los usos de la historia de vida en las ciencias sociales, Vol. I (pp. 281-296). Barcelona: Anthropos.

Archila, Mauricio (1999). ¿Es aún posible la búsqueda de la verdad? Anuario Colombiano de Historia Social y de la Cultura, (26), 249-285.

Archila, Mauricio (2003). Idas y venidas, vueltas y revueltas; protestas sociales en Colombia, 1958-1990. Bogotá: Cinep/Icanh.

Archila, Mauricio (2005). Voces subalternas e historia oral. Anuario Colombiano de Historia Social y de la Cultura, (32), 293-308.

Aróstegui, Julio (2004). La historia vivida, sobre la historia del presente. Madrid: Alianza.

Benjamin, Walter (1995). La dialéctica en suspenso. Fragmentos sobre la Historia. Santiago de Chile: Arcis/LOM.

Carretero, Mario (2007). Documentos de identidad. Buenos Aires: Paidós.

García Márquez, Gabriel (16 de febrero de 1986). Discurso ante congreso de intelectuales. El Espectador. 
Ginzburg, Carlo (1993). El juez y el historiador. Madrid: Anaya/Mario Muchnik.

Grupo de Memoria Histórica (GMH) (2013). Basta ya, Colombia: memorias de guerra y dignidad. Bogotá: Imprenta Nacional.

Gnecco, Cristóbal (2000). Historias hegemónicas e historias disidentes: la domesticación política de la memoria social. En C. Gnecco y M. Zambrano (Comps.). Memorias hegemónicas, memorias disidentes; el pasado como política de la historia. Bogotá: Icanh, Colciencias, Universiad del Cauca.

González, Eduardo y Varney, Howard (2013). En busca de la verdad. Nueva York: ICTJ.

Guha, Ranahit (2002). History at the Limit of the World-History. Nueva York: Columbia University.

Freeman, Mark (s. f.) África y sus comisiones de verdad y reconciliación. Hechos del Callejón. Acnur.

Habermas, Jürgen (1989). The New Conservatism. Cultural Criticism and the Historians Debate. Cambridge: MIT Press,

Halbwachs, Maurice (2004). La memoria colectiva. Zaragoza: Prensas Universitarias.

Hobsbawm, Eric (1998). Sobre la historia. Barcelona: Crítica.

Jaramillo, Jefferson (2014). Pasados y presentes de la violencia en Colombia. Bogotá: Pontificia Universidad Javeriana.

Jelin, Elizabeth (2003). State Repression and the Labors of Memory. Minneapolis: University of Minnesota Press.

Jelin, Elizabeth (2007). La conflictiva y nunca acabada mirada sobre el pasado. En M. Franco y F. Levin (Comps.). Historia reciente. Buenos Aires: Paidós.

Koselleck, Reinhart (1993). Futuro pasado. Barcelona: Paidós.

LaCapra, Dominick (2009). Historia y memoria después de Auschwitz. Buenos Aires: Prometeo.

Rappaport, Joanne (1990). The Politics of Memory. Cambridge: Cambridge University Press. 
Ricoeur, Paul (2008). La memoria, la historia, el olvido. México: Fondo de Cultura Económica.

Rivera, Silvia (2004). El potencial epistemológico y teórico de la historia oral: de la lógica instrumental a la descolonización de la historia. Revista Periferia, (4), 16-26.

Santos, Boaventura de Sousa (2009). Una epistemología del Sur. México: Clacso/Siglo XXI.

Sarlo, Beatriz (2005). Tiempo pasado: cultura de la memoria y giro subjetivo. Una discusión. México: Siglo XXI.

Spivak, Gayatri Ch. (2003). ¿Puede hablar el subalterno? Revista Colombiana de Antropología, 39. 297-364

Stone, Laurence (1991). Notes: History and Post-modernism. Past and Present, (131), 217-218.

Thompson, Eduard Palmer (1963). The Making of the English Working Class. Nueva York: Vintage Books.

Thompson, Eduard Palmer (1981). Miseria de la teoría. Barcelona: Crítica.

Todorov, Tzvetan (2000). Los abusos de la memoria. Barcelona: Paidós.

Traverso, Enzo (2007). El pasado, instrucciones de uso: historia, memoria, política. Madrid: Marcial Pons. 